
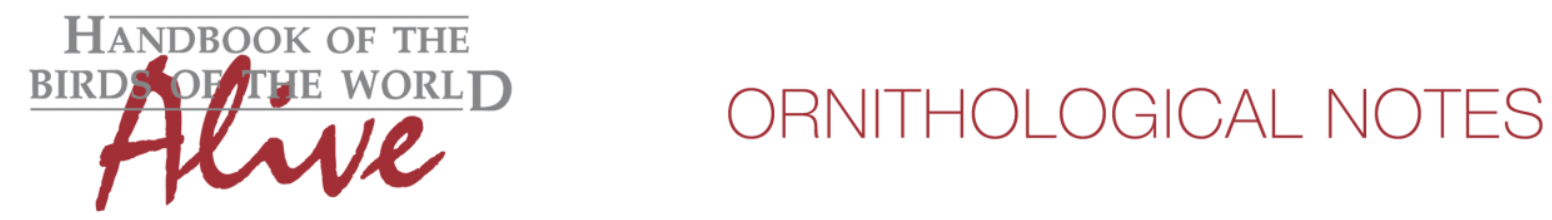

\title{
Notes on the vocalizations of Olivaceous Woodcreeper (Sittasomus griseicapillus)
}

Peter Boesman

In the following we briefly analyze and compare voice of the different races of Olivaceous Woodcreeper (Sittasomus griseicapillus). We also try to quantify the extent of any vocal differences using the criteria proposed by Tobias et al. (2010), as a support for taxonomic review. We have made use of sound recordings available on-line from Xeno Canto (XC).

It would seem that vocally, one can distinguish 6 groups:

\section{griseus group}

Song is a fast series of notes (trill or rattle) with highest pitch and amplitude about in the middle. Depending on the level of excitement, amplitude and frequency in the middle of the song varies somewhat. Within this group, there are slight differences among the different races:

S. g. jaliscensis: $15-20$ notes, $0.9-1.1 \mathrm{~s}$ long, 0.035 s note length, max. freq. $4400-6000 \mathrm{~Hz}$, min freq. $2000 \mathrm{~Hz}$

S. g. sylvioides: $22-27$ notes, $1.1-1.6 s$ long, 0.032 s note length, max freq $5200-6000 \mathrm{~Hz}$, min freq. $2200-2700 \mathrm{~Hz}$

S. g. gracileus: S. g. perijanus S. g. tachirensis no recordings on XC

S. g. griseus: Differs in starting slower, with longer more whistled notes before switching to a longer rattle. $35-42$ notes, $2.7-3.4$ s long, 0.038 s note length, max freq $4200-5200 \mathrm{~Hz}$, min freq $1700 \mathrm{~Hz}$. (S.g. griseus thus has a higher number of notes, a longer song strophe and reaches lower frequencies, which may be scored according to Tobias criteria about $2+2$ vs. other races within this group)(Fig. 1).

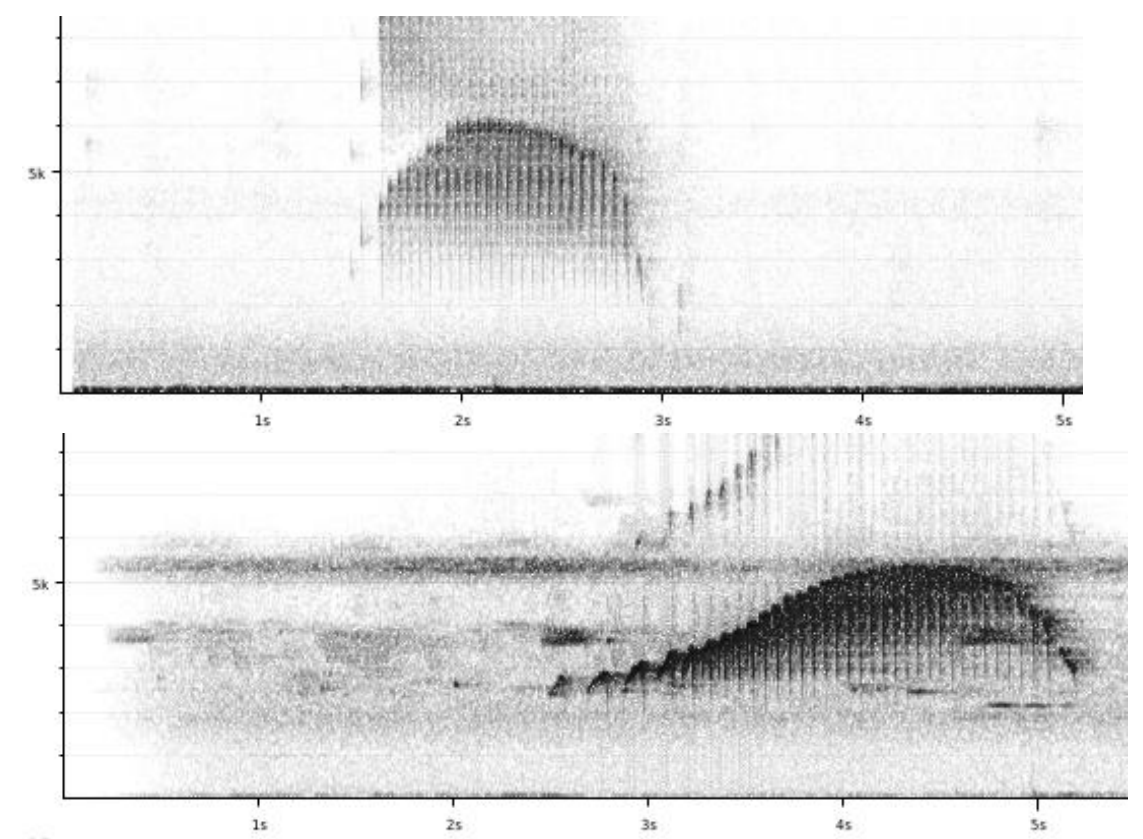

Figure 1: example of song of race sy/vioides(above) and griseus (below). 


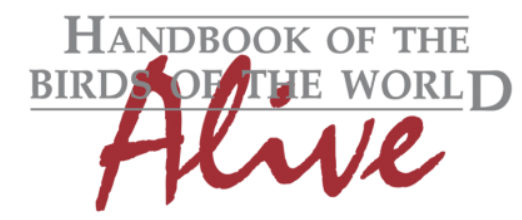

\section{ORNITHOLOGICAL NOTES}

\section{aequatorialis group}

Song is a fast series of notes (trill or rattle) with highest pitch and amplitude about in the middle. Differs from griseus group in sounding much more mellower or 'rubber-lipped'. Measurements: $32-35$ notes, $1.9-2.1$ long, 0.036 s note length, max. freq. $2000-2200 \mathrm{~Hz}$, min freq. $1000 \mathrm{~Hz}$.

Main vocal differences with the griseus group are the much lower maximum frequency (score 3) and frequency range (score 2), which leads to a total score of 5 (at most).(Fig. 2)

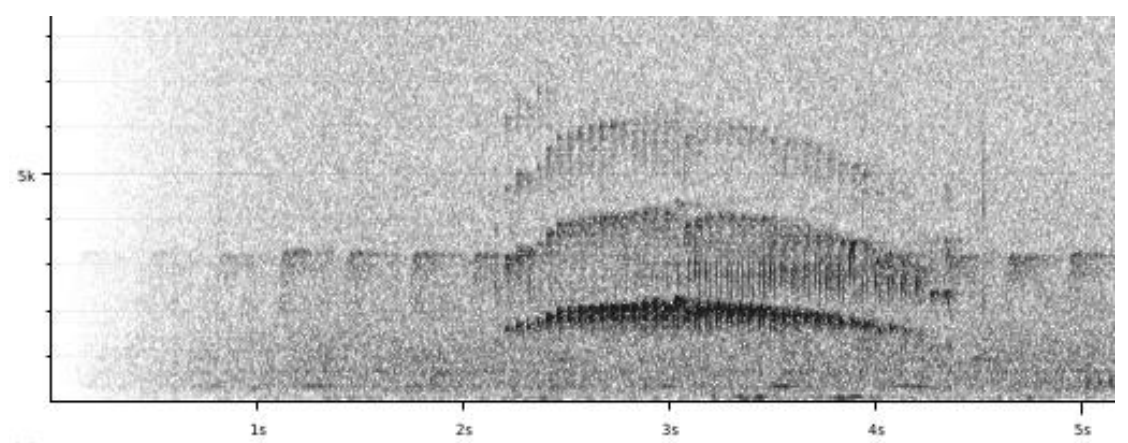

Figure 2: example of song of race aequatorialis

The above two groups differ markedly from all the following groups, primarily because song is a trill or rattle (vs. a much slower series of notes for all following groups). Vocal difference can thus be quantified based on fast pace and short note (score at least $3+3$ vs. all following groups).

griseicapillus group 1 (includes S. g. amazonus and S. g. axillaris)

Song is a series of whistles which start about flat-pitched and change into downslurred whistles. The series first increases in pitch, towards end again dropping in pitch (Fig. 3). Measurements: $6-15$ notes, $1.8-5$ s long, $0.18-0.28$ s note length, $\mathrm{min} / \mathrm{max}$ freq. c. 1600 $5000 \mathrm{~Hz}$

(S. g. transitivus: no clear recordings of song on XC, possibly different voice).

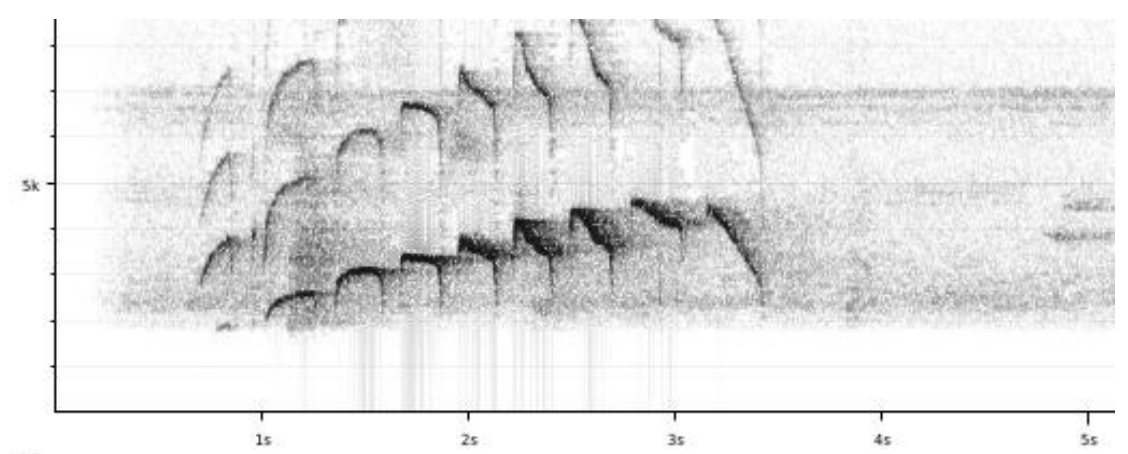

Figure 3: example of song of race amazonus 


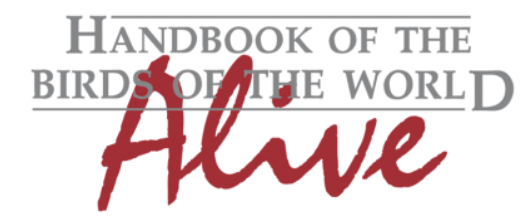

\section{ORNITHOLOGICAL NOTES}

griseicapillus group 2 (includes S. g. viridis and S. g. griseicapillus)

Song is a series of rather staccato overslurred whistles. First increasing in pitch, towards end again dropping in pitch (notes of griseicapillus shorter than in viridis). Measurements: 11-23 notes, 3.4-5.36s long, $0.08-0.17 \mathrm{~s}$ note length, $\mathrm{max} / \mathrm{min}$ freq $3900-1700 \mathrm{~Hz}$ (Fig. 4).

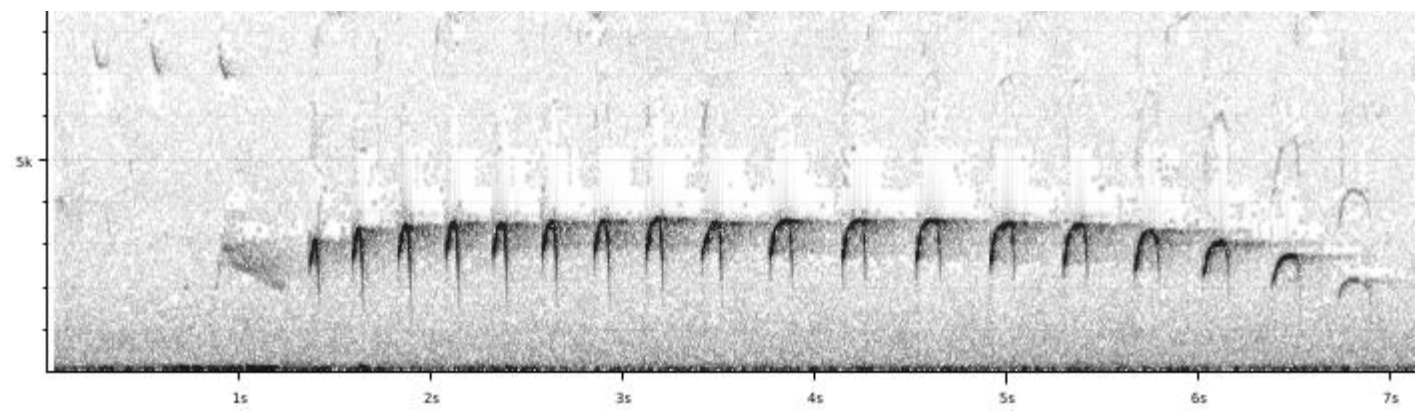

Figure 4: example of song of race griseicapillus

reiseri group (S. g. reiseri)

Song is a series of upslurred notes, at about constant amplitude and frequency over its entire length (Fig. 5). Measurements: $14-22$ notes, 3-5s long, 0.1-0.13s note length, $\mathrm{max} / \mathrm{min}$ freq. $5000-2000 \mathrm{~Hz}$.

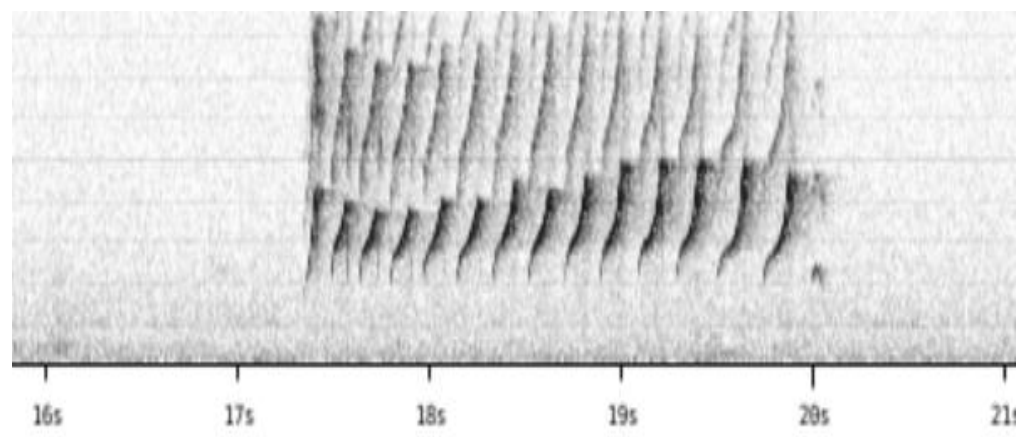

Figure 5: example of song of race reiseri

sylviellus group (includes S. g. olivaceus and S. g. sylviellus)

Song is a series of well-separated short upslurred or overslurred notes, gradually descending in pitch and often ending with some stuttering notes. Maximum amplitude in the beginning (somewhat longer with more notes and higher-pitched in sylviellus)(Fig. 6). Measurements: 8-15 notes, $2.8-7 \mathrm{~s}$ long, $0.13-0.19 \mathrm{~s}$ note length, $\mathrm{max} / \mathrm{min}$ freq c. $6000-1800 \mathrm{~Hz}$

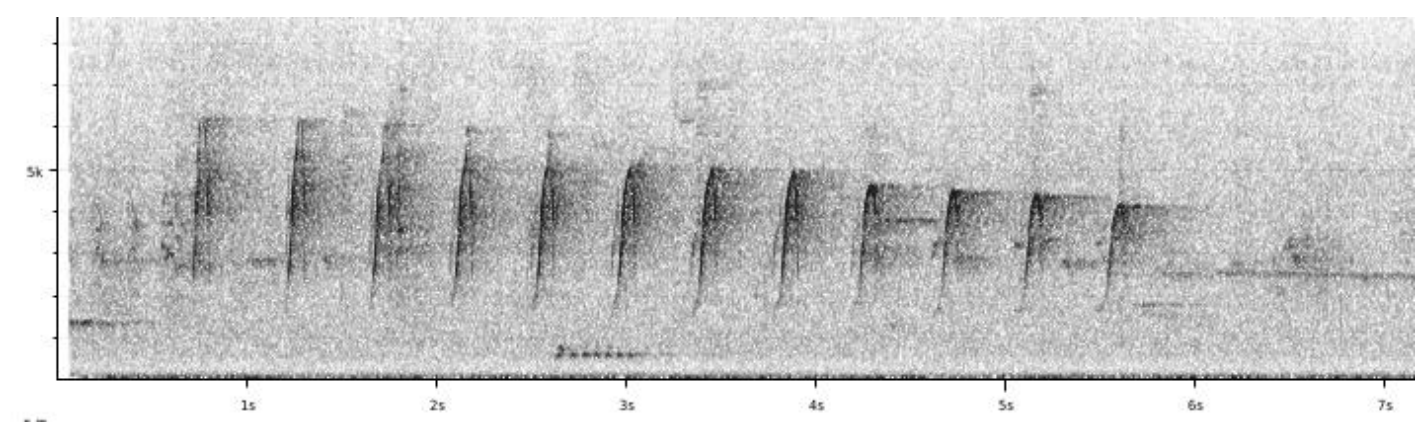

Figure 6: example of song of race sylviellus 

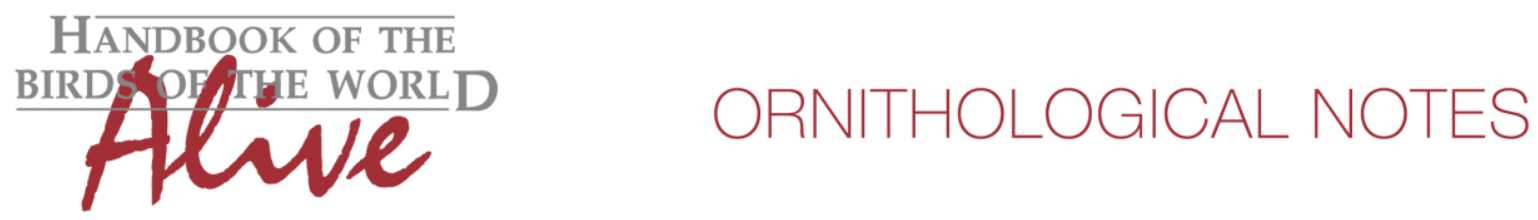

These last 4 groups are less markedly differentiated in terms of basic sound parameters, but can nevertheless be readily identified in the majority of cases.

griseicapillus group 1: unique features: long note length and note shapes griseicapillus group 2: unique features: stable note length and shape over entire series reiseri group: unique features: about constant amplitude and frequency over entire length and upslurred notes

sylviellus group: unique features: intervals longer than note length, descending pitch (and sometimes stutter at end)

We can thus conclude that voice of this complex can be divided into two major groups, characterized by respectively trilled songs and countable note series. In each of these, further subgroups can be distinguished ( 2 (or 3 ) in the former and 4 in the latter).

This note was finalized on 1st April 2015, using sound recordings available on-line at that moment. We would like to thank in particular the many sound recordists who placed their recordings for this species on XC.

\section{References}

Tobias, J.A., Seddon, N., Spottiswoode, C.N., Pilgrim, J.D., Fishpool, L.D.C. \& Collar, N.J. (2010). Quantitative criteria for species delimitation. Ibis 152(4): 724-746.

\section{Recommended citation}

Boesman, P. (2016). Notes on the vocalizations of Olivaceous Woodcreeper (Sittasomus griseicapillus). HBW Alive Ornithological Note 79. In: Handbook of the Birds of the World Alive. Lynx Edicions, Barcelona. (retrieved from http://www.hbw.com/node/931973 on 15 July 2016). 